\title{
SENSOR NEEDS AND READINESS LEVELS FOR OCEAN OBSERVING: AN EXAMPLE FROM THE OCEAN OBSERVATORIES INITIATIVE (OOI)
}

\author{
Lorraine H Brasseur $^{(1)}$, Mario Tamburri ${ }^{(2)}$, Al Pluedemann ${ }^{(3)}$ \\ (1) Consortium for Ocean Leadership, 1201 New York Avenue, NW Suite 400, Washington, DC 20005, USA, \\ Email: lbrasseur@oceanleadership.org \\ (2) Alliance for Coastal Technologies, University of Maryland Center for Environmental Science, One Williams Street, \\ Solomons, MD 20688, USA, Email: tamburri@cbl.umces.edu, \\ (3) Woods Hole Oceanographic Institution, Clark 202A, MS\#29, Woods Hole, Ma. 02543, USA, \\ Email: aplueddemann@whoi.edu
}

\begin{abstract}
The National Science Foundation's (NSF) Ocean Observatories Initiative (OOI) will implement the construction and operation of an interactive, integrated ocean observing network. The OOI will afford observations at coastal, regional, and global scales on timeframes of milliseconds to decades in support of investigations into climate variability, ocean ecosystems, biogeochemical processes, coastal ocean dynamics, circulation and mixing dynamics, fluid-rock interactions, and the sub-seafloor biosphere. The elements of the OOI include arrays of fixed and relocatable moorings, autonomous underwater vehicles, and cabled seafloor nodes. All assets combined, the OOI network will provide data from over 45 distinct types of sensors, comprising over 800 total sensors distributed in the Pacific and Atlantic oceans. The success of the OOI is based in part on identifying and adopting effective and reliable in situ instrumentation. We present the results of an OOI and Alliance for Coastal Technologies (ACT) workshop to engage members of the technology development and manufacturing communities with scientific, engineering, and agency ocean observing communities in a discussion of OOI requirements and supplier capabilities. Consensus at this workshop was reached on: (a) technology readiness levels of various ocean observing sensor types, (b) maintenance requirements, operational logistics, packaging needs for various sensor applications (platform types and deployment locations), (c) sensor interfacing relative to cyberinfrastructure, and (d) future plans for sensor innovations and refinements.
\end{abstract}

\section{OVERVIEW}

The biological, chemical, geological, and physical processes that actively shape the earth and ultimately impact society must be investigated over the spatial and temporal scales at which they occur. To characterize the processes occurring in the ocean, new types of infrastructure are needed that are capable of providing long-term, high-resolution observations of critical environmental parameters. In order to provide the U.S. ocean sciences research and management communities with access to the basic infrastructure required to make sustained, long-term and adaptive measurements in the oceans, the NSF's (National Science Foundation) Ocean Sciences Division has developed the Ocean Observatories Initiative (OOI). The OOI is an outgrowth of many years of community-wide scientific planning efforts, both nationally and internationally. As these efforts mature, the research-focused observatory network enabled by the OOI will be an important collaborator with the NOAA-led (National Oceanic and Atmospheric Administration) Integrated Ocean Observing System (IOOS) and NSF sponsored programs such as EarthScope and the Integrated Ocean Drilling Program.

The success of these efforts is based in large part on identifying and adopting effective and reliable in situ instrumentation as observing networks are being designed, deployed and expanded. To address these issues the OOI, in partnership with the Alliance for Coastal Technologies (ACT), held a workshop on 12 13 March 2009 in Portland, Oregon, entitled "Instrument Needs and Readiness Levels for Ocean Observing". The fundamental goal was to engage members of the technology development and manufacturing communities with scientific, engineering, and agency ocean observing communities in a discussion of OOI requirements and supplier capabilities. In particular, the workshop built community consensus on: (a) technology readiness levels of various ocean observing sensor types, (b) maintenance requirements, operational logistics, packaging needs for various sensor applications (platform types and deployment locations), (c) sensor interfacing relative to cyberinfrastructure, and (d) future directions for sensor innovations and refinements.

\section{OCEAN OBSERVATORIES INITIATIVE}

Unlike observational scientists on land, ocean scientists have very limited access to sustained high-resolution, multidisciplinary time series, and they cannot routinely run sophisticated analyzers in situ or command eventdriven sampling responses. This is because oceans are challenging environments to study, monitor, and model. Ocean waters are opaque to radio frequencies, corrosive, exert tremendous pressure at depth, harbor 
marine life that foul sensor surfaces, can destroy mechanical structures, and most are not easily accessible. Therefore, progress in developing the capability to collect long-term observations essential to ocean science has been hard won, at times slow, and in many cases remains insufficient.

Numerous reports [1, 3 and 4] emphasize the need for simultaneous, interdisciplinary measurements to investigate a range of phenomena, from episodic, shortlived events (tectonic, volcanic, biological, severe storms), to more subtle, longer-term changes in ocean systems such as circulation patterns, climate change, and ecosystem trends.

The OOI will meet these challenges by building a networked infrastructure for sensors that will collect ocean and seafloor data at high sampling rates over years to decades [1 and 2]. These sensors will be linked to shore using the latest communications technologies, enabling scientists to reconfigure them from their laboratories and use the incoming data in near-real time in their models. Researchers, managers, and educators from around the world will be able to take advantage of OOI's open data policy and cyberinfrastructure capabilities in distributed processing, visualization, and integrative modeling. Each of the OOI's coastal, regional and global elements will provide revolutionary ocean-observing capabilities (Fig. 1). Copper and fiber cable installed across a tectonic plate will supply continuous power and communications to commandable, multidisciplinary instrument suites. A combination of moorings and mobile samplers (ocean gliders and autonomous underwater vehicles) will collect high-resolution, time-series data at the complicated boundary between coastal and deep-ocean regimes on both the west coast and the east coast of the United States. Moored, long-term observatories stationed in the high northern and southern latitude oceans will record information critical to understanding ocean-atmosphere interactions, climate variability, and ocean dynamics and biogeochemistry. The OOI cyberinfrastructure will make available the distributed observing assets to all users in near-real time, permitting such activities as event-response sampling.

Since at least 1988 , the ocean sciences community has been developing and refining OOI science, engineering, and outreach concepts (e.g. [3-7]). The OOI design developed from two main technical directions: seafloor observatories linked with submarine cables to land that provide power and Internet connectivity; and buoy observatories that provide locally generated power to seafloor and platform instruments and use a satellite link to land and the Internet. A third technical elementintegration of mobile assets such as autonomous underwater vehicles (AUVs) — emerged during program planning. These three technical developments were nurtured by NSF through the support of numerous related projects and workshops [3, 5 and 10]. These activities led to the vision of three observatory scalescoastal, regional, and global-within one distributed, integrated network (Fig. 1).

The planning and design of the OOI came under management of the Consortium for Ocean Leadership (OL) in 2007 when the Joint Oceanographic Institutions became part of this new corporation. In December of 2007, NSF conducted a Preliminary Design Review of the OOI. Based on the success of this review, a Final Network Design was presented in November 2008 [1 and 2] before the NSF cost/schedule and technical review panels and in May 2009 the National Science Board (NSB) gave its endorsement to the OOI. NSF and ARRA (American Recovery \& Reinvestment Act) funding was received and construction started in September 2009.

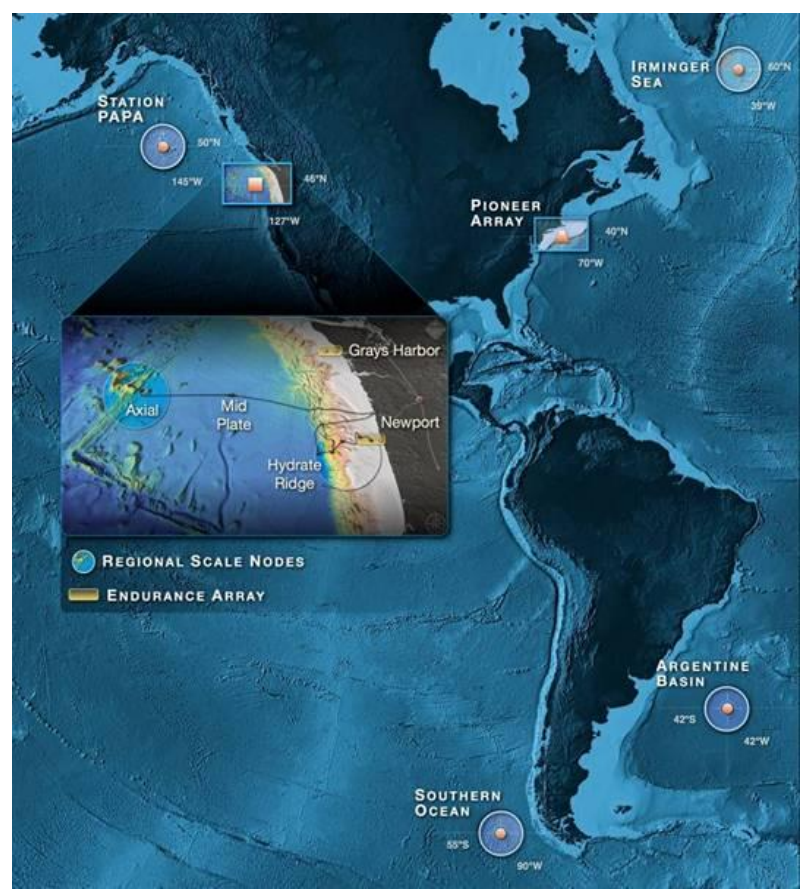

Figure 1. Locations of planned OOI infrastructure.

\section{WORKSHOP GOALS}

The primary goal of the OOI Instrumentation Needs and Readiness Levels workshop was to inform instrument developers and vendors of the OOI core sensor needs (including the different platforms and locations where these sensors will be deployed) and the OOI approach to acquiring and incorporating sensors to the OOI infrastructure. The requirements for OOI core sensor specifications were discussed and the Technology Readiness Levels (TRL) and Maintenance Classes that OOI scientists and engineers developed were also reviewed. Breakout discussions with workshop participants then focused on building consensus on, and recommendations for, issues of technology maturity, 
instrument packaging, sensor interfaces, deployment and maintenance logistics, and sensor cyberinfrastructure $(\mathrm{CI})$ interfaces. Finally, future plans for sensor development both relative to the needs of OOI and to the most recent technology advances were discussed.

\subsection{OOI Technology Readiness Levels}

Technology Readiness Level (TRL) is a measure used by several US and international agencies to assess the maturity of evolving technologies prior to incorporating them into an operational system or application. Based on the U.S. National Aeronautics and Space Administration (NASA) nine-stage TRL descriptions [8] and the oceanographic sensor assessment from the OceanSensors08 (Symposium on Multi-disciplinary Sensors and Systems for Autonomous Observations of the Global Ocean) workshop [9], the OOI Project Scientist and Sensors working group established a fivelevel set of TRL definitions applicable to the OOI core sensors (Tab. 1). Each OOI Core Sensor type will be scored in each of these five categories with respect to their deployment platform (e.g. fixed moored, fixed seafloor, mobile profiler, mobile glider, etc.) and operating environment (e.g. offshore, nearshore, shallow water, deep water).

\subsection{Core Sensors}

Determination of the OOI core sensor suite began with the identification of scientific themes and goals of the OOI as outlined in the OOI Science Prospectus [1] and continued through the science requirements derived from the traceability matrices described therein. The traceability exercise allowed OOI scientists and engineers to follow scientific questions from requirements through to core sensors and infrastructure design. The OOI planning process identified over 45 core sensor types that can be further classified into distinct sensor classes that represent measurements made by similar sensors. For example, the CTD (Conductivity-Temperature-Depth) sensor class encompasses all instruments measuring temperature and conductivity regardless of platform or intended sampling frequency. In addition, the sensor classes were divided into five locations representing the vertical extent of sampling best addressed by each class. The 28 sensor classes and their locations are described in Tab. 2.

\begin{tabular}{|c|c|}
\hline OOI TRL & Description \\
\hline $\begin{array}{l}\text { 1. Proof of Concept / } \\
\text { Development }\end{array}$ & $\begin{array}{l}\text { Lowest level of technology readiness. Scientific research begins to be translated into applied } \\
\text { research and development. The application is speculative and there is no proof or detailed } \\
\text { analysis to support the assumption. Includes analytical studies and laboratory studies to } \\
\text { physically validate analytical predictions of separate elements of the technology. }\end{array}$ \\
\hline 2. Research: Prototype & $\begin{array}{l}\text { The basic technological components are integrated with reasonably realistic supporting } \\
\text { elements so that the technology can be tested in a simulated or relevant environment. } \\
\text { Prototype instrument packages have been used to collect data in research studies of technology } \\
\text { or environmental parameter. }\end{array}$ \\
\hline 3. Research: Proven & $\begin{array}{l}\text { Technology has not been commercialized, but is clearly beyond prototype stage. Multiple } \\
\text { instrument packages have been fabricated and deployed for extended periods under expected } \\
\text { environmental conditions. Publications exist which demonstrate scientific utility of data. }\end{array}$ \\
\hline 4. Commercial & $\begin{array}{l}\text { Technology has been proven to work in its final form and under expected environmental } \\
\text { conditions. Instruments are in commercial production with appropriate supporting materials } \\
\text { (replacement parts, operations manual, etc.) }\end{array}$ \\
\hline 5. Operational & $\begin{array}{l}\text { Actual application of commercial or research-proven technology in its final form and under } \\
\text { sustained operational conditions. Independent, third-party evaluation or application that } \\
\text { demonstrates reliable long-term field operations. }\end{array}$ \\
\hline
\end{tabular}

Table 1: OOI Recommended Technology Readiness Levels 
Based on these sensor classes, the OOI sensors can also be grouped into the different disciplines represented by the measurements made by each sensor. These disciplines are defined as Physical Oceanography, (including meteorology), Biological Oceanography, Chemical Oceanography, Geological Oceanography, and engineering sensors (modems). Figure 2 shows the breakdown of the sensor classes by discipline.

\subsection{OOI Deployment Platforms and Design}

The OOI core sensors will be distributed across multiple platforms in Atlantic and Pacific coastal regions of the United States, several open ocean high-latitude locations, and on Juan de Fuca Plate off the U.S. Pacific Northwest coast (Fig. 1). The OOI design calls for sensors to be deployed on cabled seafloor nodes, on

\begin{tabular}{|c|c|}
\hline Sensor Class & Vertical location \\
\hline Acoustic velocity profilers & Water column \\
\hline Temperature/conductivity/depth & Water column \\
\hline Passive acoustic hydrophones & Water column \\
\hline Inverted echosounders & Water column \\
\hline $\mathrm{pH}$ & Water column \\
\hline Single point velocity measurements & Surface \\
\hline Wave measurements & Surface \\
\hline $\begin{array}{c}\text { Basic Meteorology Measurements (winds } \\
\text { speed and dir, air temp, rel. humidity, } \\
\text { precipitation, etc) }\end{array}$ & Surface \\
\hline Partial pressure of $\mathrm{CO} 2$ & Surface \\
\hline Direct covariance fluxes & Surface \\
\hline fluorescence & $\begin{array}{c}\text { Shallow water or near } \\
\text { surface }\end{array}$ \\
\hline $\begin{array}{l}\text { Nitrate measurements using UV absorption } \\
\text { methods }\end{array}$ & Water column \\
\hline $\begin{array}{l}\text { Nutrient measurements (Nitrate, Nitrite, } \\
\text { etc.) using wet chemistry }\end{array}$ & Water column \\
\hline Dissolved oxygen & $\begin{array}{c}\text { Shallow water or near } \\
\text { surface }\end{array}$ \\
\hline Spectral irradiance & $\begin{array}{c}\text { Shallow water or near } \\
\text { surface }\end{array}$ \\
\hline Photosynthetically active radiation & $\begin{array}{c}\text { Shallow water or near } \\
\text { surface }\end{array}$ \\
\hline Optical absorption & $\begin{array}{l}\text { Shallow water or near } \\
\text { surface }\end{array}$ \\
\hline Zooplankton sonar & $\begin{array}{c}\text { Shallow water or near } \\
\text { surface }\end{array}$ \\
\hline Mass spectrometers & Bottom geo/chem/bio \\
\hline Seafloor temperature & Bottom geo/chem/bio \\
\hline Seismometers & Bottom geo/chem/bio \\
\hline Cameras (still and motion) & Bottom geo/chem/bio \\
\hline Benthic flow & Bottom geo/chem/bio \\
\hline DNA analyzers & Bottom geo/chem/bio \\
\hline Hydrothermal vent chemistry & Bottom geo/chem/bio \\
\hline Wet chemistry sampling & Bottom geo/chem/bio \\
\hline Pressure (seafloor) & Bottom geo/chem/bio \\
\hline Acoustic modems & Engineering \\
\hline
\end{tabular}

Table 2: OOI Sensor classes and sampling locations 


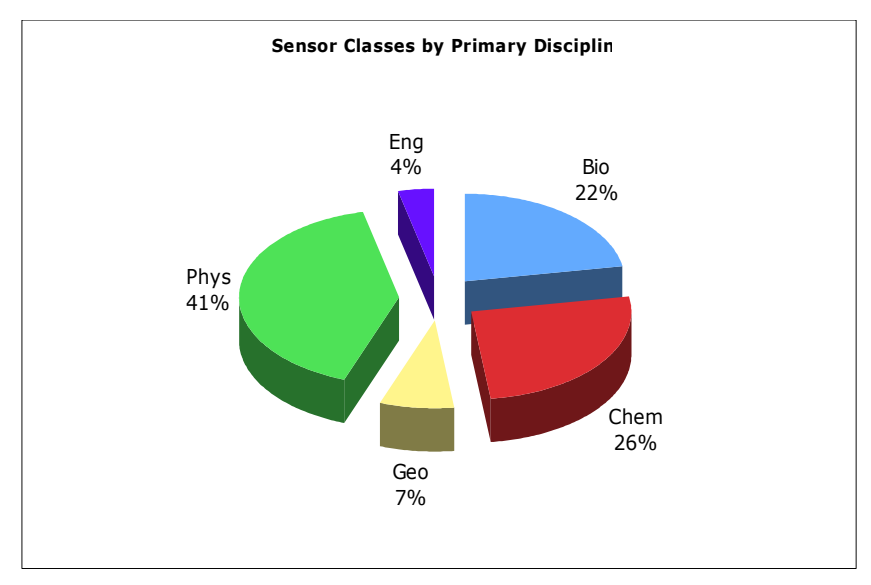

Figure 2. OOI Sensor classes (see Tab. 2) broken down by primary oceanographic discipline

surface and subsurface moorings, and on mobile assets such as vertical profilers, gliders and AUVs. Detailed descriptions of each platform type are provided in the OOI Final Network Design [2] and an example is provided in Fig. 3.

\subsection{Cyberinfrastructure}

The science applications that are addressed by the ocean observatory span many themes, including climate change and biogeochemical cycling, ecosystem dynamics, turbulent mixing and biophysical interactions, and the dynamics of subseafloor fluids and life in continental margins. This broad, multidisciplinary range of science questions is addressed with a distributed network of deep ocean moorings, a plate-scale Regional Scale Nodes (RSN) element, a long-term coastal time series Endurance Array, and a coastal adaptive sampling Pioneer Array. This distributed, interconnected network of observing hardware enables science on multiple time and space scales that separate components behaving independently of each other would not. Advanced CI capabilities provide the user two-way interactivity, command \& control, and data discovery through both real-time instruments and historical data archives. The user requirements driving the CI design are diverse, and flow from specific science needs that have been identified in a series of National Research Council publications, community science documents, and targeted OOI user workshops.

The OOI CyberInfrastructure (CI) constitutes the integrating element that links and binds the physical infrastructure into a coherent system-of-systems. Indeed, it is most appropriate to discuss "the OOI network" as an integrated whole that allows scientists and citizens to view particular phenomena irrespective of the source of the observation data (e.g. coastal, global, regional, ships, satellites, IOOS).

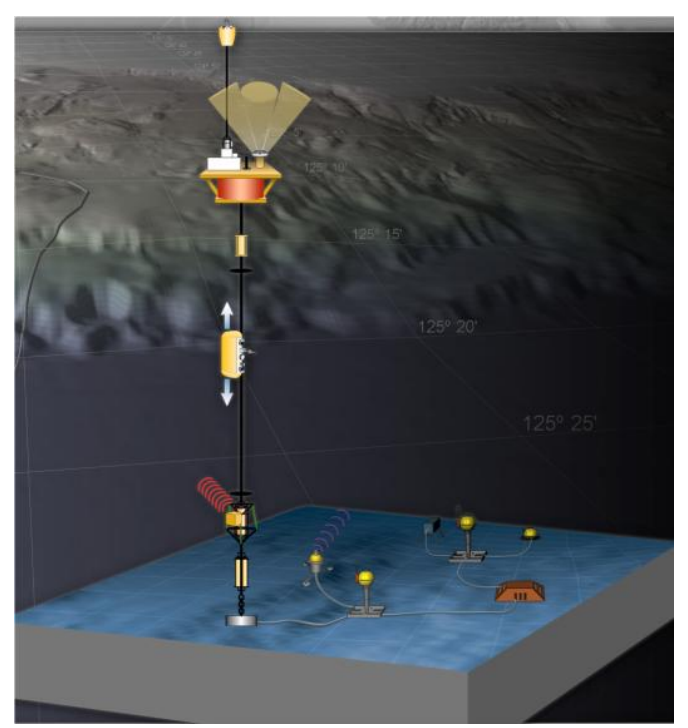

Figure 3. Subsurface mooring to be deployed at two sites on the Regional Scale Nodes and at the offshore site of the Endurance Array showing the use of a winched profiler mounted on the subsurface floatation/instrument housing, wire-crawler profilers moving along the mooring line below, and the connection to a seafloor cable.

\section{WORKSHOP OUTCOMES}

\subsection{Physical interfaces and packaging}

Workshop participants concluded that there are two key challenges relating to physical interfaces and packaging of sensors for large-scale installments such as the OOI. The first involves the many mounting differences, sampling environments, and power options for the same or similar sensors on the various platforms. The second issue concerns standardization of the physical interfaces of different sensors and sensor groupings on the same platform. For both cabled and non-cabled applications, the physical interfaces and the data interfaces must be known and must be compatible in order for instrumentation to be grouped into platform specific configurations that work as seamless units in terms of power and data transmission.

Other considerations that are necessary for successful deployment of multi-sensor platforms include colocation and interference between instruments, including electric fields generated by other instruments and acoustic interference, especially between current meters, modems, and hydrophones. These issues will need to be addressed in a systematic way for a successful system. Power, physical space for sensors, sensor sample volume, and varying warm up and response times will also need to be addressed for the many multi-sensor platforms of the OOI. The list of other key considerations developed at the workshop for 
packaging sensors into tight groupings on a platform include:

- The location of pumps (e.g. for conductivity cells) relative to other instruments on the sampling platform and relative to the wake from the platform and other instruments.

- Use of a seawater ground with instruments that ground to pressure cases.

- Timing issues, especially on platforms that allow large spatial separation and sensors such as seismometers that require microsecond timing.

- Disturbance of the flow by the platform. Note that this can be ameliorated by several options including allowing the platform to weathervane or instrumenting multiple sides of the platform with redundant sensors.

- Grounding and corrosion issues related to dissimilar metals and materials interacting with each other and inappropriate materials for connectors in certain environments.

- Compass calibration and tilt issues, such as sensitivity of compass to battery placement, and neighboring sensors/batteries. One solution to this issue may be modular packaging, i.e. pre-packaging all sensors in one unit before adding the unit to a platform. Another possibility is a common compass/tilt sensor, with the relevant data to be distributed among several sensors.

- Connector issues, especially with regard to appropriate pressure ranges and platform types.

It became clear during discussions at the workshop that while standardization of sensors and sensor interfaces has many advantages, there is a tradeoff between keeping sensor variety to a minimum while installing them on a diversity of platforms. Some examples of this include connectors designed for shallow water $(\sim 100 \mathrm{~m})$ applications versus connectors designed for deep $(\sim 3000 \mathrm{~m})$ applications and sensors designed for cabled applications versus sensors designed for mobile platforms. For example, designing all sensors to meet the $3000 \mathrm{~m}$ requirements may be costly and inefficient in that it would result in over-engineering of the sensors for many applications. A compromise must be reached between limiting the number of sensor and interface classes for different environments/purposes and allowing for appropriate platform and environment-specific sensor specialization. Participants identified several important considerations with regard to standardization. These included voltage issues, sampling issues, and both software and physical interface issues.
Voltage discussions focused on the type of power to be provided to the many different OOI platforms, the physical placement of the voltage conversion mechanisms for instruments requiring different voltage than supplied, output power, transient loads, and shielding issues. In most cases, 12, 24, and/or 48 volt power will be supplied to all platforms and there may be the possibility for 6-volt power for some uncabled applications. One challenge will lie in supplying both 12 and 24-volt power to different instruments on the same platform and properly configuring the power output at the various ports. Other challenges will be in conditioning power and the transient loads that need to be considered in power bus designs. Shielding issues will be especially important in the case of electromagnetic (EM) noise.

Interface discussions focused on configurable sampling strategies, different standards and protocols available for "Plug and Play", and the possible use of some of these standards. Possible standards to consider are IEEE (Institute of Electrical and Electronics Engineers) 1451.4 (see http://ieee1451.nist.gov/ for details) and PUCK protocols (Programmable Underwater Connector, with Knowledge) (http://www.mbari.org/pw/puck.htm) [11]. One of the differences between the two is the amount of data throughput possible through the different interface standards. Sensing the voltage requirement using the software interface and configuring the port appropriately is another possible function of the software interface. The adoption of different protocols such as serial RS-232 and RS-485 for serial devices is generally up to the manufacturer and can possibly be influenced by community needs. Rather than serial connections, it may be useful to transition to USB (Universal Serial Bus) protocols, however, long cables may preclude this and investment by manufacturers to support the overhead associated with USB may not be cost effective due to up-front investment, risk, and expected short cycle time of this standard in the community, also RS-232 is low power, a necessary quality for much of the OOI system, while USB is not.

Physical Interface issues center around the usefulness of standardization to a specific connector type across many different instruments. In order to accommodate a large number of different instruments, the connector may have to be somewhat large in size. However, a connector with a large form factor would not be optimal in a small packed device or platform such as a glider, so the concept of a common connector to accommodate platforms as diverse as gliders and large RSN benthic nodes may not be not realistic. Multiple classes of connections will be necessary for the different platforms, but recognizing this and limiting these classes to as few as possible will be a necessary 
part of OOI design and construction. One solution to standardizing the interface would be to specify pinouts for the principle wires for all instruments, therefore allowing several different styled connectors to be interchangeable. It was noted that this is an excellent situation for OOI to assume a leadership role, which would help the industry in the long run by creating a set of standards to which they can adhere. Close interaction between the sensor manufactures and the providers of mobile assets (gliders and AUVs) and profilers will be necessary. In some cases, sensor vendors will need to provide the sensor without the typical packaging in order to install it on profilers, AUVs and gliders. The form factor, size, and weight may drive different implementations. The final aspect of physical interfaces that must be accounted for, as mentioned above is one of acoustics. Specifically, in addition to acoustic interference between different acoustic sensors in the same vicinity, acoustic modem placement and installation will need to be optimized to effectively relay data but not interfere with other sensors.

\subsection{Fouling}

Fouling, both biological and chemical/physical, is one of the most pressing concerns for any long-term ocean observatory. Knowing the type of expected fouling, the state of the art mitigation techniques and the propensity for instruments to foul to varying degrees in different environments will inform the design. The degree of fouling will be different for fixed platforms, vertical profilers, and mobile platforms and also for surface versus bottom and near coastal versus open ocean deployments. Participants provided insight on mobile platforms based on experience with gliders and Argo (Array for Real-time Geostrophic Oceanography) floats, which suggests they are less susceptible to biofouling than static platforms. In general, boundaries (e.g. fronts, pycnoclines) are areas of greater biofouling versus the interior (open) ocean. Biofouling in the surface/photic zone, near shore, and with low flow conditions is usually a greater problem. Near bottom sensors can be fouled via re-suspension, settling and growth. It will be necessary to categorize sensors with regard to utility and survivability in the different regimes and platforms. One useful approach for refining the fouling impact is to field test various options jointly with ACT, using resources and facilities designed for these purposes. There is consensus that fouling is a very specific issue relating to the sensor, platform, location, depth, duty cycle, time, and the nature of fouling. The suite of biofouling control and remediation methods can be examined and applied to the different classes of instrumentation. Some fouling mitigation examples follow below.
For CTD conductivity cells solutions include using Tributyl tin (TBT) or copper applied directly to the conductivity cell, limiting internal flow of water through the cell or limiting flow through the cell by changes in cell geometry. Alternatively, changing the type of cell to ceramic electro-conductivity with an embedded piezo-electric oscillator to discourage particles (1-5 micron in diameter) from attaching is a possibility. Other approaches involve the use of electro-chlorination, $\mathrm{H} 2 \mathrm{SO} 4$, or bleach injection.

For optical sensors, the use of copper coating, the use of UV light sources and ozone are all possibilities, but the latter may consume too much power and be too short lived for most long term applications. Another solution is the use of multiple or duplicate sensors with fouled sensors rotated out of service and replaced by fresh sensors. The use of difference-based measurement techniques (e.g. comparison of multiple, simultaneously logged channels) can also be used to circumvent typical fouling scenarios for optical instruments.

For acoustic instruments, microorganism fouling is generally not a problem and antifouling paints (containing TBT or Copper) are typically used with good results to prevent macrofouling.

For wet chemical sensors (water chemistry such as nitrate, nitrite, phosphate, etc.), biofouling is influenced by movement of the fluid, time exposure to the sample fluid, and the nature of the platform. Copper enclosures with bleach injection, controlled flow paths to minimize membrane exposure to biology and changes in the diffusion length are all fouling mitigation techniques used for these sensors. For other chemical based sensors (e.g. auto-analyzers), pressurized containers and acetic acid via bleed injection can be used. Pumps are a problem with wet chemical sensors and are often the failure point. There are suites of approaches now available with more options being explored, including use of liquid TBT and solid-state methods.

The most important consequence of fouling is degraded data quality, but it is often difficult to determine when data have degraded beyond usability. Frequent calibration, both pre- and post-deployment, is recommended and is further discussed in the logistics and operations section of this paper. However, the methods of applying post-calibration data to collected data streams are not always straightforward or well documented. There was great concern from participants that post-calibration should not be used to correct degraded or drifted data unless great care is taken and the nature of the data degradation is well 
understood. While options such as taking samples on deployment, during periodic servicing, and upon retrieval may be useful, it may never be possible to post-correct all data for all instruments. Thus the importance of mitigating fouling as much as possible for sensors that will be deployed on the OOI for up to a year in some cases. For some instruments such as pCO2 sensors, in-situ self-calibrations may also be possible. The concept of onboard standards for other sensors is also a possible future solution.

\subsection{Sensor Readiness}

The discussion of sensor readiness focused on the OOI TRLs and the categorization of various sensors into these readiness categories. Two of the most critical factors affecting readiness level are deployment duration and duty cycle operation. These will be important to many OOI sensors, as they are to any sensors mounted on cabled and uncabled, long-term observatories. The OOI specifies continuous deployments of up to a year for many of the sensors and platforms. While it is felt that these goals, though ambitious, are not unreasonable, there is concern that the categorization of many COTS sensors as high readiness and low risk may lead to assumptions that the technology is fully mature and requires no further development. The OOI needs to have a common set of standards based on science requirements with a focus on long-term processes that need to be tracked. This will drive the level of accuracy that each sensor class must meet. The TRL for a specific sensor may be different based on different deployment applications and these varying levels for the same sensor or instrument need to be taken into account when evaluating overall levels.

Many recommendations for the OOI to continually improve and assess readiness levels of the sensors on the evolving system came from this discussion. The following major recommendations will help the OOI assess and upgrade sensor readiness levels. An OOI review panel made up of both OOI and outside community members will be needed to review risk categorizations on an ongoing basis, assessing risk as a combination of technical readiness and maintenance aspects. Sensor requirements need to be specified and available to the technical and scientific communities, in part to serve as pre-notification for vendors to anticipate changes and revisions to sensors as the OOI progresses. Along this theme, OOI shall notify vendors of sensor requirements such as sensor response time, sampling frequency, vertical and horizontal resolution, adaptive sampling needs, deployment environment (depth and location), local environment (platform type) in which sensors need to perform, profiling speed of platforms, and other key elements of sensor specifications. This necessitates two-way communication to get information on new and/or improved sensors from vendors to users (OOI) and changes in requirements, sampling protocols to vendors. One useful addition to these mechanisms would be a funding stream to support the testing of sensors for prolonged periods in different environments. ACT can verify the performance of mature sensors under diverse conditions and applications and demonstrate capabilities of young sensors. This testing service helps build a market through increasing awareness of sensor capability. The US EPA's (Environmental Protection Agency) Environmental Technology Verification program is another option that defines a testing protocol and provides for comparison of vendor claims; however, a fee is charged for this evaluation. The communication between the OOI and the community is stressed in the evaluation and improvement of sensors that will be part of the OOI.

\subsection{Logistics, Operations, and Maintenance Strategies}

The logistics of platform-sensor design and interaction, initial deployment, and sampling schemes, are key to OOI success. Mobile assets, fixed water column platforms, and fixed, cabled seafloor platforms will all require consideration in OOI operations and maintenance strategies. It is understood that the science requirements must drive the instrument and platform designs and that the type of platform influences the parameters being measured through the different and limited types of sensor that can be placed on each platform type. All platforms were given consideration in these discussions.

AUVs and gliders present a particular challenge due to their size and limited power options. In order to be successful, vendors will need details of the OOI concept of operations for mobile platforms and the specifications expected for these systems. As OOI begins to publish these specifications, a continuing three-way dialog between the OOI, instrument manufacturers and platform manufacturers will need to take place so they can work together to further solutions to the limited space and power issues. It is not always possible to separate the vehicle from the measurement; the platform and sensor must be engineered together in order to achieve the best data. Instrument interactions on the same mobile asset will also be very important in determining the design and placement of instrument packages, even more than on other platforms because of the tight space and power restrictions on these platforms.

The discussion focused in a large part on fixed platforms including surface buoys, fixed shallow $(<100 \mathrm{~m})$ and deep platforms, including the vertical profilers 
on these moorings. Both cabled and uncabled moorings were considered. Several options for servicing sensors on these fixed platforms were discussed. Diver servicing is one option that is considered unrealistic and too costly with very high associated risks for most of the OOI assets. Servicing surface moorings from alongside ships was also considered too high risk, especially with the possibility of heavy weather at many of the mooring sites, especially the global sites. Pulling moorings on board the vessel in order to service and/or redeploy was deemed the only practical option for servicing moorings involving surface buoys.

Local ground truth data and/or intercomparison with sensors on the same mooring was also identified as essential to the overall operational strategy of the OOI. Recommendations included bringing similar sets of sensors on cruises during scheduled mooring replacement cruises and collecting data with these during the servicing, deploying the replacement buoys and sensors before retrieving the in-situ buoys for overlap of measurements, and use of the retrieval vessel's available instrumentation such as ADCPs (Acoustic Doppler Current Profilers) and CTDs as a check against the surface and profiling moored instruments.

The cruises that provide maintenance for the OOI network infrastructure will also provide opportunities to conduct intercomparisons of shipboard and in-situ sensors. Ships will need to remain on station for sufficient time periods to conduct comparative measurements while maintaining a fixed position proximal to the in-situ sensors via dynamic positioning or other precise navigation. As many intercomparisons of OOI sensor measurements with other measurements as possible will be necessary to ensure validity of the sensor data over long periods of time. Intercomparisons during the annual deployment and retrievals of OOI moorings, especially global moorings, may be supplemented by ships of opportunity (other research vessels in the area, cruise ships, etc.) that can/may be equipped with sensors comparable to the OOI (including XBT (Expendable Bathythermograph), XCTD (Expendable Conductivity Temperature Depth), etc.).

Vertical profilers and the instruments located on these platforms will require servicing at different time intervals depending on environment, fouling and power sources for the profilers and the instruments mounted upon them. Tradeoffs will need to be made among sampling frequency, speed of profiler and vertical/temporal resolution required of the data from each sensor. The OOI is at the forefront in terms of the use of profilers as part of a long time-scale ocean-wide observatory.
Sea floor instruments in some cases are relatively low maintenance and will function for years without semiannual or even annual calibrations or replacements. Some examples of these are water column acoustics and seismic instruments. On the other hand, wet chemistry instruments on the benthic instrument packages will require frequent in-situ calibration in order to verify the data. Interference among acoustic instruments, acoustic and seismic instruments and platform interference to these types of instruments will also need to be addressed before they can be deployed in proximity to each other. This is also true for many of the other sea floor instruments including the wet chemistry instrumentation.

\section{CONCLUSIONS}

The OOI encourages community collaborations to solve the problems of placing groups of disparate sensors in different environments and different supporting platforms. The duration of the OOI project and its requirements for long-term, nearly autonomous functionality, will drive innovations and increases in sensor longevity. While many of the OOI core sensors are at a high readiness level, many factors, including interface compatibility, fouling mitigation, and power consumption will need to be carefully considered and addressed.

In the coming years, OOI and the international oceanographic science and technology communities will need to continue open dialogue in order to foster the discussion and information exchanges that will lead to the successful instrumentation and deployment of the OOI. To further this goal, a continuing series of OOI technology, cyberinfrastructure, and science community workshops are planned for the future, including fall 2009 and spring 2010 science community workshops. Additionally, OOI participation in many US and international conferences and workshops like OceanObs'09 will be an important part of our strategy for oceanographic community engagement and involvement.

\section{REFERENCES}

1. Consortium for Ocean Leadership, Inc. 2007. Ocean Observatories Initiative (OOI) Scientific Objectives and Network Design: A Closer Look. Washington, DC. http://www.oceanleadership.org/files/Science_Prospect us_2007-10-10_lowres_0.pdf.

2. Consortium for Ocean Leadership, Inc. 2007. Final Network Design. Washington, DC. http://www.oceanleadership.org/wpcontent/uploads/2009/08/110100000_FND_OOI_2009-11-03_ver_2-02_public.pdf. 
3. National Research Council. 2000. Illuminating the Hidden Planet: The Future of Seafloor Observatory Science. National Academy Press, Washington, DC.

4. ORION Executive Steering Committee. 2005. Ocean Observatories Initiative Science Plan. Joint

Oceanographic Institutions, Inc. Washington, DC. http://orionprogram.org/PDFs/OOI SP summary.pdf.

5. Joint Oceanographic Institutions, Inc. 2006. Ocean Observatories Initiative: Scientific Objectives and Network Design. Washington, DC.

6. Joint Oceanographic Institutions, Inc. 2007. ORION'S Ocean Observatories Initiative Conceptual Network Design: A Revised Infrastructure Plan. Washington, DC.

http://orionprogram.org/PDFs/RevisedOOICND08Mar $\underline{07 . p d f}$.

7. ORION Science and Technical Advisory Committee. 2006. Recommendations for Changes to the Conceptual Network Design of ORION's Ocean Observatory Initiative. Joint Oceanographic Institutions, Inc., Washington, DC.

8. Mankins, J.C., 1995. Technology Readiness Levels, NASA Advanced Concepts Office, Office of Space Access and Technology, http://www.hq.nasa.gov/office/codeq/trl/.

9. Waldmann, C., Tamburri, M., Prien, R. D., and Fietzek, P.: Assessment of sensor performance, Ocean Sci. Discuss., 6, 1687-1716, 2009, http://www.ocean-scidiscuss.net/6/1687/2009/.

10. R. Detrick, D. Frye, J. Collins, J. Gobat, M. Grosenbaugh, R. Petitt, A. Pluedeman, K. von der Heydt, B. Wooding (WHOI); J. Orcutt, J. Berger, R. Harriss, F. Vernon (SIO); J. Halkyard, E. Horton (DOT), 2000. DEOS Moored Buoy Observatory Design Study. Woods Hole Oceanographic Institution Technical Report, August 2000, 98 pp. Sponsored by the National Science Foundation, Oceans Sciences Division, www.coreocean.org.

11. Headley, K.L., D. Davis, D. Edgington, L. McBride, T.C. O'Reilly, M. Risi. 2003. Managing Sensor Network Configuration and Metadata in Ocean Observatories Using Instrument Pucks. Third International Workshop on Scientific Use of Submarine Cables and Related Technologies, 25-27 June 2003. 